\title{
Evolution of the haemagglutinin gene of the influenza A(H1N1)2009 virus isolated in Hong Kong, 2009-2011
}

G C Mak' ${ }^{1}$ C K Leung ${ }^{1}$, K C Cheng ${ }^{1}$, K Y Wong ${ }^{1}$, W Lim (wllim@pacific.net.hk) ${ }^{1}$

1. Virology Division, Public Health Laboratory Services Branch, Centre for Health Protection, Department of Health, Kowloon, Hong Kong

Mak GC, Leung CK, Cheng KC, Wong KY, Lim W. Evolution of the haemagglutinin gene of the influenza $\mathrm{A}\left(\mathrm{H}_{1} \mathrm{~N}_{1}\right) 2009$ virus isolated in Hong Kong, 2009-2011. Euro Surveill. 2011;16(9):pii=19807. Available online: http://www.eurosurveillance.org/ViewArticle.aspx?Articleld=19807

Phylogenetic analysis of the haemagglutinin (HA) gene shows that the influenza $A\left(\mathrm{H}_{1} \mathrm{~N}_{1}\right) 2009$ viruses collected in Hong Kong clustered in two main branches characterised by the E391E and E391K amino acids. The main branch E391K evolved in two sub-branches with N142D and S202T mutations that first appeared in March and July 2010, respectively, with the latter becoming the predominant strain. These genetic variants that emerged display similar antigenic characteristics. Concurrent with genetic surveillance, laboratories should continue monitoring the circulating viruses antigenically.

\section{Introduction}

Influenza $A\left(\mathrm{H}_{1} \mathrm{~N}_{1}\right)_{2009}$ virus is a reassortant of swine, avian and human influenza viruses which is antigenically different from seasonal influenza $A\left(\mathrm{H}_{1} \mathrm{~N}_{1}\right)$ viruses circulating previously [1]. In Hong Kong, the first case was detected in a visitor from Mexico on 1 May 2009. The infection spread locally in June 2009 and reached its peak in September 2009 (Figure 1).

Intense selection by the host immune system drives antigenic change which results in the continuous replacement of circulating strains with new variants to re-infect individuals and cause widespread illness. Although the influenza $A\left(\mathrm{H}_{1} \mathrm{~N}_{1}\right) 2009$ virus has been circulating worldwide since April 2009, and the haemagglutinin ( $\mathrm{HA}$ ) antigenic sites have been under increasing antibody-mediated selection pressure [2], recent isolates were still antigenically similar to the vaccine virus $A / C a l i f o r n i a / 7 / 2009$ [3-5]. It is important to characterise the HA in order to monitor any emerging variants while the virus continues to circulate in the community. Genetically, one of the characteristic differences between the epidemic viruses collected between March and September 2009 and the vaccine virus [6] was substitution at position 220 with almost all currently circulating viruses having S220T amino acid change (the amino acid positions of HA sequence are denoted using full $\mathrm{HA}$ coding region, i.e. amino acid position 18 corresponds to position 1 of the HA without the signal peptide) $[7,8]$. In addition to this mutation, the E391K substitution grew rapidly globally between
July and December 2009 [9] and two other substitutions, N142D and S202T, have recently been described in $2010[4,5]$.

Here we describe temporal sequence changes in the $\mathrm{HA}$ gene of the influenza $\mathrm{A}\left(\mathrm{H}_{1} \mathrm{~N}_{1}\right)_{2} 009$ virus isolated in Hong Kong from 2009 to 2011.

\section{Sample collection and sequence analysis}

For this analysis, we included 338 full HA sequences of influenza viruses isolated from respiratory samples obtained from 40 public and private hospitals and clinics in Hong Kong between June 2009 and January 2011. The proportion of sequences analysed was in accordance with the positive isolation rate in each institution. Only one isolate from each patient was included. With the exception of June 2009, when only two full HA sequences were included at least four isolates from patients with either mild or severe respiratory illness were selected randomly per month. The PCR amplification and DNA sequencing of the full length of HA gene were performed using six different in-house designed primers: H1v-moo44-F (5'-AGTATACGACTAGCAAAAGCAGGGG-3'), H1V-0323-R ( 5'-TAACACGTTCCATTGTCTGA-3'), H1V-0898-R (5'-TGGGTGTTTGACAAGTTGTA-3'), H1V-0805-F( 5'-AGATATGCATTCGCAATGGA-3'), H 1V1348-F( 5'-AGAACTTTGGACTACCACGA-3'), H 1V-1752-R (5' - CCGTGTCAGTAGAAACAAGGGTGTTT-3'). H 1Vmo044-F, H1v-0898-R, H1v-0805-F and H1v-1752-R were used as the PCR primers; in addition to these four primers, $\mathrm{H}_{1 \mathrm{~V}}-0323-\mathrm{R}$ and $\mathrm{H} 1 \mathrm{~V}-1348-\mathrm{F}$ were used as the sequencing primers.

Sequence data were compiled and edited using the Lasergene sequence analysis software package (DNASTAR Inc). Multiple alignment of nucleotide sequences and translation of amino acid sequence was carried out by using BioEdit (http://www.mbio. ncsu.edu/bioedit/bioedit.html). In order to show the major evolutionary pattern of HA gene, only sequences shared by more than one isolate were included for the construction of a phylogenetic tree using MEGA (http:// www.megasoftware.net/). According to this strategy, 33 sequences representing 217 isolates (64.2\%, 
217/338) were selected for phylogenetic analysis. One sequence (A/HongKong/2213/2010) that has been used as reference in EuroFlu Weekly Electronic Bulletin [10] and the National Institute for Medical Research [11] was also included for reference.

\section{Results}

Over the study period, the amino acid at position 391 was either E or K. Phylogenetic analysis of the HA gene showed that the influenza $A\left(\mathrm{H}_{1} \mathrm{~N}_{1}\right)_{2009}$ viruses collected in Hong Kong clustered into two main branches characterised by this position (Figure 2 ).

With the emergence of E391K viruses in July 2009, the proportion of viruses with E391E fluctuated between $8 \%$ and $98 \%$ during the period from July 2009 to February 2010 and was gradually displaced by the evolving E391K viruses (Figure 3).

Within the main branch E391E, a sub-branch characterised by $\mathrm{S} 145 \mathrm{P}$ reported previously [11] was also observed (Figure 2). The four strains A/Hong Kong/2213 (the reference strain used in EuroFlu Weekly Electronic Bulletin and the National Institute for Medical Research), A/Hong Kong/1886/2010, A/Hong Kong/2212/2010, A/ Hong Kong/2200/2010 collected between April and July 2010 belonged to this sub-branch and all had V216A and I312V substitutions while A/Hong Kong/2200/2010 and A/Hong Kong/2212/2010 also had additional substitutions K180T and P288S (not shown in Figure 2).
In the main branch with the E391K substitution, two sub-branches characterised by N142D and S202T mutation were observed (Figure 2). The isolates in the subbranch characterised by N142D first appeared in March 2010 and its proportion appeared to peak in May 2010 and declined thereafter. The isolates in the sub-branch with the mutations S202T first appeared in July 2010 and their proportion increased sharply displacing the isolates with $\mathrm{N} 142 \mathrm{D}$ in September 2010. This subbranch continued to predominate since then (Figure 3).

\section{Discussion}

In Hong Kong, with a sizable proportion of the population becoming infected during the first wave of pandemic in September in 2009 [12] and the implementation of a vaccination programme using a monovalent vaccine in December 2009 [13], the resulting immunological pressure may have driven virus evolution as shown by the displacement of E391E by E391K, a site important for membrane fusion [9], and the emergence of the two genetic sub-branches characterised by $\mathrm{N}_{142 \mathrm{D}}$ and $\mathrm{S} 202 \mathrm{~T}$ amino acid substitutions involving the antigenic sites $\mathrm{Sa}$ and $\mathrm{Sb}$ respectively. These antigenic sites contain many amino acids involved in neutralising epitopes near the receptor binding pockets [2]. All the genetic variants that emerged, however, displayed similar antigenic characteristics when assessed by haemagglutination inhibition assay using A/California/07/2009 ferret antisera [3-5]. Although a single amino acid substitution involving one antigenic site may be sufficient to cause antigenic change, more

\section{FIGURE 1}

Monthly influenza virus isolation rates by type and subtype, Centre for Health Protection, Department of Health, Hong Kong, 2009-2011

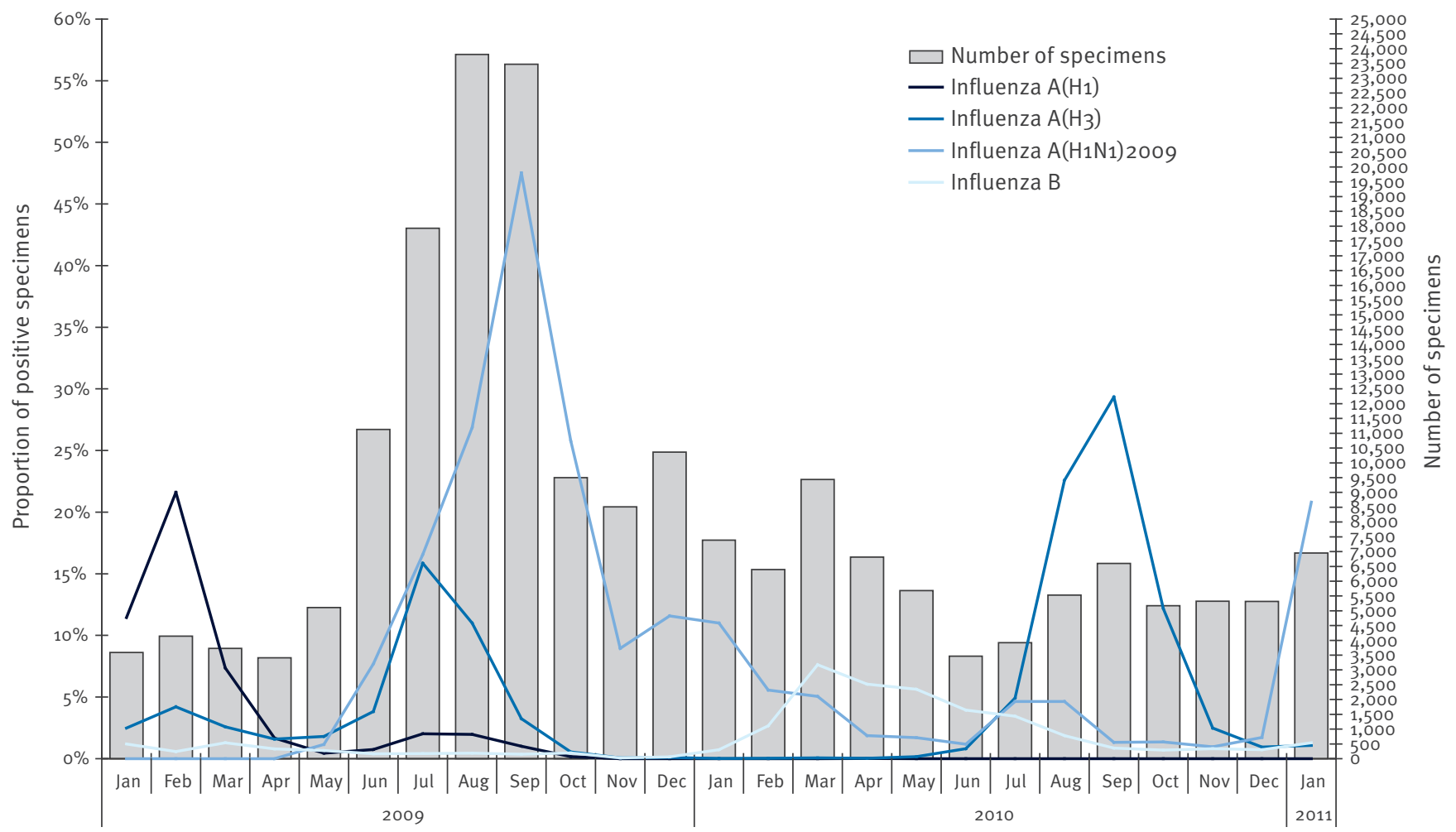




\section{FIGURE 2}

Phylogenetic tree of the full-length haemagglutinin sequences of influenza A(H1N1)2009 virus circulating in Hong Kong from 2009 to 2011

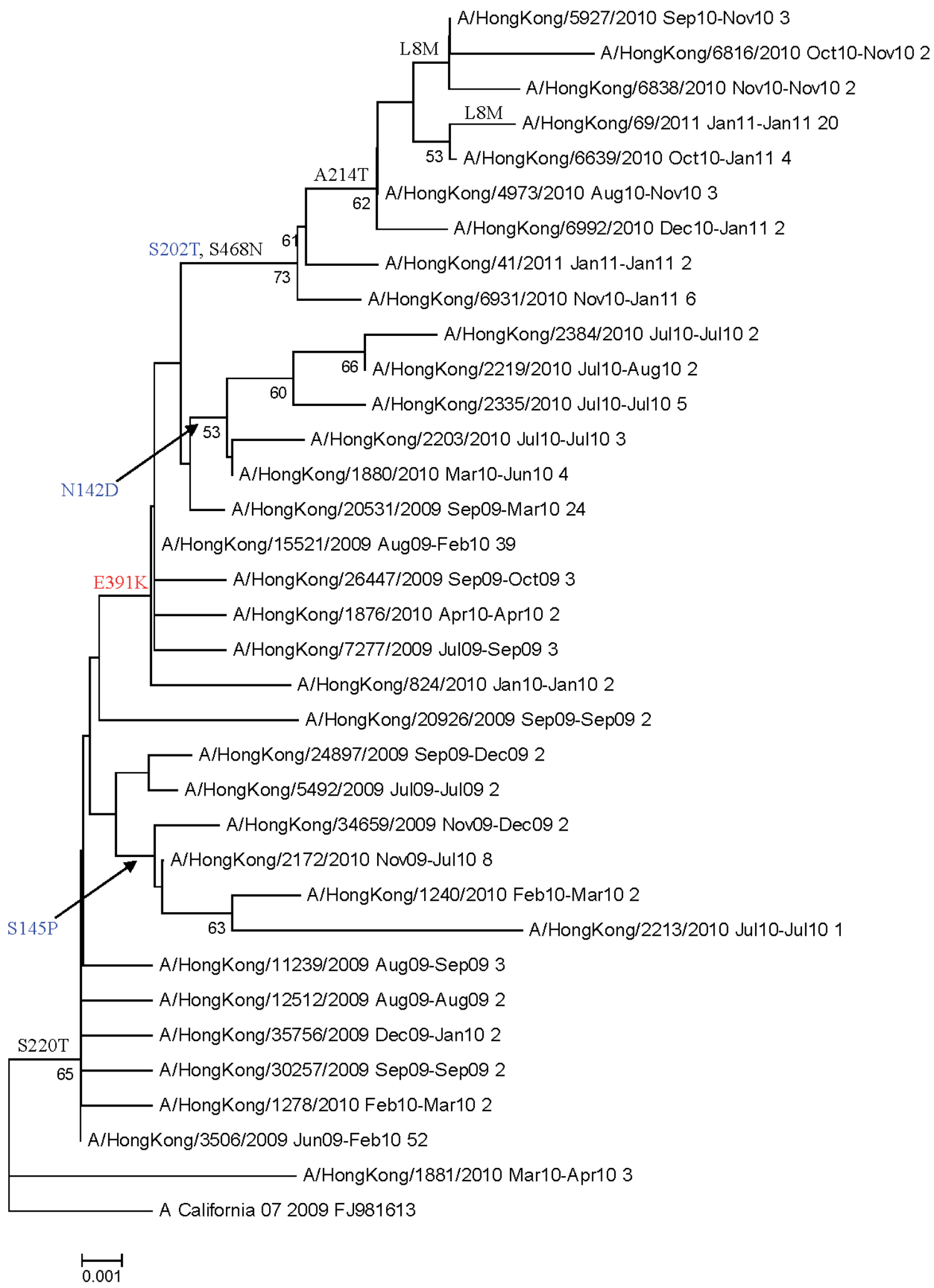

Only the sequences shared by more than one isolate were included for the construction of a phylogenetic tree. The phylogenetic analysis was performed by use of the MEGA programme and the neighbour-joining method. The percentages of bootstrap frequencies over $50 \%$ are indicated. The tree was rooted with the vaccine strain A/California/o7/2009. Amino acid substitutions in sub-branches are described under the internal branches. Each leaf node contains three sections: designated name of isolate, the time period isolates with this sequence were detected, the number of isolates with this sequence.

The main branch substitution is shown in red colour and the sub-branch substitutions are shown in blue colour. 
commonly antigenic drift variants of epidemiological importance have resulted from changes of at least four amino acids across two or more antigenic sites $[14,15]$. In fact, the prevalence of the influenza $A\left(\mathrm{H}_{1} \mathrm{~N}_{1}\right)_{2} 2009$ virus remained low in Hong Kong between March and December 2010 and was displaced during that period by the highly active influenza type $\mathrm{A}\left(\mathrm{H}_{3} \mathrm{~N}_{2}\right)$ virus (Figure 1).

However, at the start of the traditional winter influenza season in Hong Kong in January 2011, the influenza $A\left(H_{1} N_{1}\right)_{2009}$ virus belonging to the genetic subbranch with E391K and S202T substitutions increased in number rapidly and became the predominant strain. While it is interesting to note the emergence of new genetic sub-branches and see how viruses circulating worldwide are selected and share the same HA mutations, mutations may often be an evolutionary 'dead end' and do not have much significance [16]. It is thus important that laboratory surveillance continues to include virus isolation and monitors the circulating viruses antigenically. Concurrent genetic surveillance would facilitate early detection of antigenic sites that are selected for the virus to escape immunological restraint.

\section{References}

1. Garten RJ, Davis CT, Russell CA, Shu B, Lindstrom S, Balish $A$, et al. Antigenic and genetic characteristics of swine-origin $2009 \mathrm{~A}\left(\mathrm{H}_{1} \mathrm{~N}_{1}\right)$ influenza viruses circulating in humans. Science. 2009;325:197-201.

2. Igarashi M, Ito K, Yoshida R, Tomabechi D, Kida H, Takada A. Predicting the antigenic structure of the pandemic ( $\left.\mathrm{H}_{1} \mathrm{~N}_{1}\right) 2009$ influenza virus hemagglutinin. PLoS One. 2010;5(1):e8553.

3. World Health Organization (WHO). Recommended viruses for influenza vaccines for use in the 2010-2011 northern hemisphere influenza season. Geneva:WHO; [Accessed 15 Feb 2011]. Available from: http://www.who.int/csr/disease/ influenza/201002_Recommendation.pdf

4. Barr IG, Cui L, Komadina N, Lee RT, Lin RT, Deng Y, et al. A new pandemic influenza $A\left(\mathrm{H}_{1} \mathrm{~N}_{1}\right)$ genetic variant predominated in the winter 2010 influenza season in Australia, New Zealand and Singapore. Euro Surveill. 2010;15(42):pii=19692. Available from: http://www.eurosurveillance.org/ViewArticle. aspx?Articleld $=19692$

5. Ellis J, Galiano M, Pebody R, Lackenby A, Thompson C, Bermingham A, et al. Virological analysis of fatal influenza cases in the United Kingdom during the early wave of influenza in winter 2010/11. Euro Surveill. 2011;16(1): pii=19760. Available from: http://www.eurosurveillance.org/ViewArticle. aspx?Articleld $=19760$

6. Fereidouni SR, Beer M, Vahlenkamp T, Starick E. Differentiation of two distinct clusters among currently circulating influenza $A\left(\mathrm{H}_{1} \mathrm{~N}_{1}\right) \mathrm{v}$ viruses, March-September 2009. Euro Surveill. 2009;14(46):pii=19409. Available from: http://www. eurosurveillance.org/ViewArticle.aspx?Articleld=19409

7. Yang H, Carney P, Stevens J. Structure and Receptor binding properties of a pandemic H1N1 virus hemagglutinin. PLoS Curr. 2010;2:RRN1152.

8. Ikonen N, Haanpää M, Rönkkö E, Lyytikäinen O, Kuusi M, Ruutu $P$, et al. Genetic diversity of the 2009 pandemic influenza $A\left(\mathrm{H}_{1} \mathrm{~N}_{1}\right)$ viruses in Finland. PLoS One. 2010;5(10):e13329.

\section{FIGURE 3}

Monthly proportion of influenza A(H1N1)2009 viruses characterised by E391E or E391K with either N142D or S202T, Centre for Health Protection, Department of Health, Hong Kong, 2009-2011 (n=338)

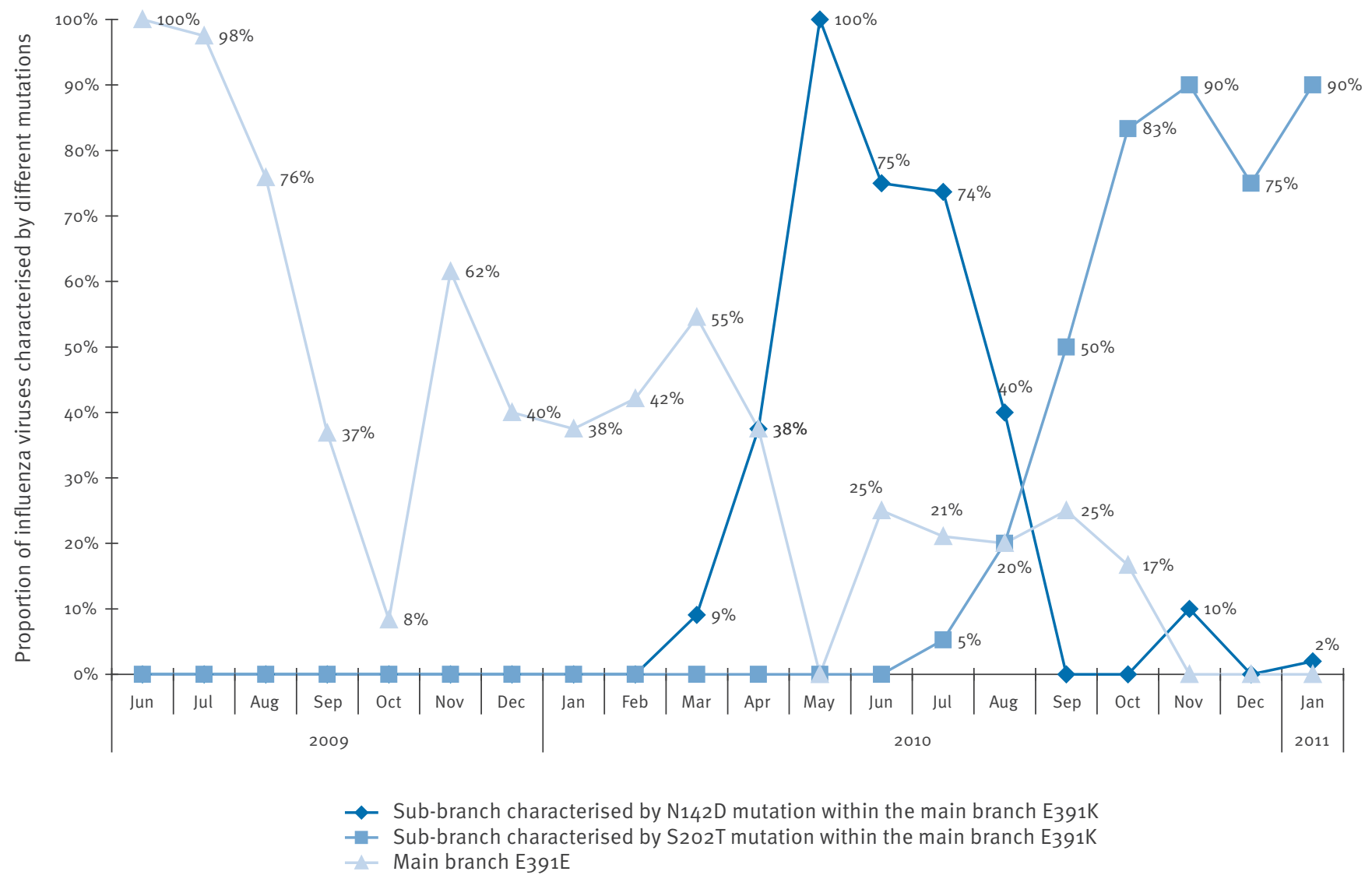


9. Maurer-Stroh S, Lee RT, Eisenhaber F, Cui L, Phuah SP, Lin RT. A new common mutation in the hemagglutinin of the $2009\left(\mathrm{H}_{1} \mathrm{~N}_{1}\right)$ influenza A virus. PLoS Curr. 2010;2:RRN1162.

10. World Health Organization (WHO). EuroFlu Weekly Electronic Bulletin. Influenza season 2010-2011. Geneva:WHO. [Accessed 15 Feb 2011]. Available from: http://www.euroflu.org/cgi-files/ bulletin_v2.cgi

11. MRC National Institute for Medical Research. WHO Influenza Centre London. Report prepared for the WHO annual consultation on the composition of influenza vaccine for the Southern Hemisphere September 2010. [Accessed 15 Feb 2011]. Available from: http://www.nimr.mrc.ac.uk/documents/about/ interim-report-sep-2010.pdf

12. Wu JT, Ma ES, Lee CK, Chu DK, Ho PL, Shen AL, et al. The infection attack rate and severity of 2009 pandemic $\mathrm{H}_{1} \mathrm{~N}_{1}$ influenza in Hong Kong. Clin Infect Dis. 2010;51(10):1184-91.

13. Centre for Health Protection. Scientific Committee on Vaccine Preventable Diseases. Recommendations on Seasonal Influenza Vaccination for the 2010/11 Season. [Accessed 15 Feb 2011]. Available from: http://www.chp.gov.hk/files/pdf/ recommendations on seasonal influenza vaccination for the 201011 season eng.pdf

14. Ferguson NM, Galvani AP, Bush RM. Ecological and immunological determinants of influenza evolution. Nature. 2003;422(6930):428-33

15. Fitch WM, Bush RM, Bender CA, Subbarao K, Cox NJ. The Wilhelmine E. Key 1999 Invitational lecture. Predicting the evolution of human influenza A. J Hered. 2000;91(3):183-5.

16. Steinhauer DA. Influenza A virus haemagglutinin glycoproteins. In Wang Q, Tao YJ editors. Influenza: Molecular Virology. Wymondham: Caister Academic Press; 2010. p. 69-108. 